\title{
Inflammation induced by lipopolysaccharide does not prevent the vitamin $A$ and retinoic acid-induced increase in retinyl ester formation in neonatal rat lungs
}

\author{
Lili $\mathrm{Wu}^{1}$ and A. Catharine Ross ${ }^{2 *}$ \\ ${ }^{1}$ Department of Nutritional Sciences, 110 Chandlee Laboratory, Pennsylvania State University, University Park, \\ PA 16802, USA \\ ${ }^{2}$ Department of Nutritional Sciences, Huck Institute for Life Science, Pennsylvania State University, University Park, PA \\ 16802, USA \\ (Submitted 21 May 2012 - Final revision received 29 June 2012 - Accepted 27 July 2012 - First published online 5 September 2012)
}

\section{Abstract}

Vitamin A (VA) plays an important role in post-natal lung development and maturation. Previously, we have reported that a supplemental dose of VA combined with $10 \%$ of all-trans-retinoic acid (VARA) synergistically increases retinol uptake and retinyl ester (RE) storage in neonatal rat lung, while up-regulating several retinoid homeostatic genes including lecithin:retinol acyltransferase (LRAT) and the retinolbinding protein receptor, stimulated by retinoic acid 6 (STRAO). However, whether inflammation has an impact on the expression of these genes and thus compromises the ability of VARA to increase lung RE content is not clear. Neonatal rats, 7-to 8-d-old, were treated with VARA either concurrently with lipopolysaccharide (LPS; Expt 1) or $12 \mathrm{~h}$ after LPS administration (Expt 2); in both studies, lung tissue was collected $6 \mathrm{~h}$ after VARA treatment, when RE formation is maximal. Inflammation was confirmed by increased $I L-6$ and chemokine (C-C motif) ligand 2 (CCL2) gene expression in lung at $6 \mathrm{~h}$ and C-reactive protein in plasma at $18 \mathrm{~h}$. In both studies, LPS-induced inflammation only slightly reduced, but did not prevent the VARA-induced increase in lung RE. Quantitative RT-PCR showed that co-administration of LPS with VARA slightly attenuated the VARA-induced increase of LRAT mRNA, but not of STRA6 or cytochrome P450 26B1, the predominant RA hydroxylase in lung. By $18 \mathrm{~h}$ post-LPS, expression had subsided and none of these genes differed from the level in the control group. Overall, the present results suggest that retinoid homeostatic gene expression is reduced modestly, if at all, by acute LPS-induced inflammation and that VARA is still effective in increasing lung RE under conditions of moderate inflammation.

\section{Key words: Vitamin A supplementation: Neonates: Lungs: Inflammation: Homeostasis}

Vitamin A (VA) is required for normal lung development in the pre- and post-natal periods, yet VA storage is low in the human lung at birth. Premature delivery is one of the major factors that contributes to severe VA deficiency and puts very-low birth weight preterm infants at high risk for developing pulmonary diseases such as respiratory distress syndrome and bronchopulmonary dysplasia ${ }^{(1-3)}$. Supplementing VA directly to newborns improves the infant's VA status and has also produced promising results in animal models for reducing lung injury and dysfunction ${ }^{(3-6)}$. Other studies have indicated that the administration of all-trans-retinoic acid (RA), a biologically active metabolite of VA, to neonatal animals is capable of inducing alveolar formation and the repair of epithelial lesions and increasing surfactant synthesis in lung ${ }^{(7-10)}$. Retinyl ester (RE), the storage form of VA, is recognised as constituting an essential endogenous pool of retinoid for the formation of bioactive compounds, including RA, which are critical for normal differentiation $^{(11)}$.

RA is believed to exert much of its influence on development and cell differentiation through regulation of gene transcription $^{(12,13)}$. Several important genes that are involved in retinoid homeostasis are also regulated by RA. In a previous study, we have shown that stimulated by retinoic acid 6 (STRA6), a retinol-binding protein receptor that mediates cellular retinol uptake ${ }^{(14)}$, lecithin:retinol acyltransferase (LRAT), an enzyme that converts retinol to its storage form, RE, as well as cytochrome P450 26B1 (CYP26B1), a cytochrome $\mathrm{P} 450$ that catalyses the oxidation of $\mathrm{RA}^{(15)}$, are tightly regulated by RA in the neonatal lung ${ }^{(16)}$. Interruption

Abbreviations: CCL2, chemokine (C-C motif) ligand 2; CRP, C-reactive protein; CYP26B1, cytochrome P450 26B1; LPS, lipopolysaccharide; LRAT, lecithin:retinol acyltransferase; RA, retinoic acid; RE, retinyl ester; STRA6, stimulated by retinoic acid 6; VA, vitamin A; VARA, supplemental dose of vitamin A combined with $10 \%$ of all-trans-retinoic acid. 
of the expression of these genes might alter the balance of retinol metabolism in the lung tissue.

It was suggested in the same study that VA storage in the neonatal lung is increased efficiently by administering VA orally in combination with $10 \%$ of all-trans-RA (VARA) ${ }^{(17,18)}$. When VA and RA were mixed together in a molar ratio of 10:1 and delivered orally, VARA was shown to produce a synergistic increase in lung RE formation, about 4- to 5-fold above the increase due to an identical amount of VA given without $\mathrm{RA}^{(17)}$. A metabolic tracer study showed that the administration of RA redirects part of the flow of the supplemental $\left[{ }^{3} \mathrm{H}\right]$ retinol into the lungs in VARA-treated neonates ${ }^{(16)}$. Investigation of the molecular mechanism of the VARA synergy revealed that RA acts as a regulator of VA homeostasis by rapidly up-regulating several retinoid regulatory genes, including STRA6, LRAT and CYP26B1 in the neonatal lung ${ }^{(16)}$, thus promoting RE formation more efficiently. Simultaneously, the VA component of VARA provides the retinol substrate for this process.

Inflammation is very often observed in preterm infants or infants with a weakened immune system ${ }^{(2,4,19)}$. During the inflammatory response, proinflammatory cytokines such as TNF- $\alpha$, IL- $1 \beta$ and IL- 8 are secreted by alveolar macrophages, fibroblasts, type II pneumocytes and endothelial cells in the early inflammatory response upon the stimulation of inflammatory agents ${ }^{(20)}$. These cytokines recruit circulating neutrophils and macrophages to the local sites of injury or infection and subsequently release higher amount of cytokines and chemokines to initiate a sequence of injurious events ${ }^{(21)}$. As an organ with a large surface area exposed to the outside, the lung is vulnerable to exogenous pathogens, allergens or chemicals. Increased levels of proinflammatory cytokines and chemokines have been detected in the airways of preterm infants at various stages of developing bronchopulmonary dysplasia ${ }^{(22,23)}$. Risk factors contributing to the inflammatory responses in the lung include inappropriate resuscitation, oxygen toxicity, mechanical ventilation, pulmonary and/or systemic infection ${ }^{(24)}$, which are most common causes of respiratory inflammation in newborn or premature infants. Inflammation is also known to alter the expression of many genes, including genes in the cytochrome P450 (CYP) family $^{(25)}$. An in vivo study in rat liver suggested that inflammation induced by administration of lipopolysaccharide (LPS) or polyinosinic acid-polycytidylic acid (poly-IC) significantly opposes the induction of CYP26A1 and CYP26B1 expression by RA ${ }^{(26)}$. It is unknown whether inflammation in the lungs attenuates or may have no effect on the VARA-induced synergy in RE formation.

In the present study, we investigated whether LPS-induced inflammation may prevent or attenuate the VARA-mediated increase in RE formation and regulation of LRAT and STRA6 in neonatal rat lungs. We also investigated CYP26B1, as its regulation could contribute to alterations in the rate of clearance of retinoids from the lung.

\section{Experimental methods}

\section{Materials and dose preparation}

VA (all-trans-retinyl palmitate) and all-trans-RA were purchased from Sigma-Aldrich. As described previously ${ }^{(18)}$, these two agents were mixed in a molar ratio of 10:1 at final concentrations of 0.05 and $0.005 \mathrm{M}$, respectively, in rapeseed oil for the oral dose. A solution of LPS from Pseudomonas aeruginosa (List Biological Laboratory) was prepared in a concentration of $10 \mu \mathrm{g} / \mathrm{ml}$ in sterile saline. Rapeseed oil and saline were used as placebos for VARA and LPS, respectively.

\section{Animals and experimental designs}

Animal procedures were approved by the Institutional Animal Use and Care Committee of The Pennsylvania State University. Two experiments were, according to the time of LPS administration, relative to the time of VARA supplementation in neonatal rats. In Expt 1, LPS and VARA were co-administered $6 \mathrm{~h}$ before the collection of lung tissue. In Expt 2, LPS was administered $12 \mathrm{~h}$ before VARA to induce inflammation at the time of VARA supplementation; in both experiments, tissue was collected $6 \mathrm{~h}$ after VARA treatment, when lung RE formation is essentially complete ${ }^{(18)}$. In each experiment, 7- to 8-d-old Sprague-Dawley rat pups that had been delivered and were nursed by VA-adequate dams were assigned randomly to four groups that received rapeseed oil (control), LPS alone, VARA or both LPS and VARA ( $n$ 4-5 pups per group).

At the beginning of each experiment, the pups were weighed and the dose of VARA was determined by weight, $0 \cdot 4 \mu \mathrm{l}$ of the dose described above per $g$ of body weight or approximately $6 \mathrm{mg}$ retinol and $0.6 \mathrm{mg} \mathrm{RA} / \mathrm{kg}$. The dose was delivered directly to the rat pup's mouth by micropipette. The $P$. aeruginosa LPS was injected intraperitoneally as a single dose, equal to $200 \mu \mathrm{g}$ of LPS $/ \mathrm{kg}$. In both studies, the neonates were individually euthanised by isoflurane inhalation $6 \mathrm{~h}$ after treatment with VARA. Lung tissue was dissected, frozen immediately in liquid $\mathrm{N}_{2}$ and stored at $-80^{\circ} \mathrm{C}$ for later analysis.

\section{Plasma anti-C-reactive protein antibody enzyme-linked immunosorbent assay}

Plasma anti-C reactive protein (CRP) was quantified by a rat CRP ELISA test kit (Life Diagnostic, Inc.), following the manufacturer's instructions. A standard of serially diluted control serum was included and titres of antibody were calculated based on this standard curve. One titre unit was defined as the dilution fold that produced $50 \%$ of the maximal optical density for the standard sample.

\section{Retinoid analysis}

Lung VA concentration was quantified, as described previously, as total retinol ( $\mathrm{RE}+$ retinol), which has been shown to be $>90 \% \mathrm{RE}$ and $<10 \% \mathrm{retinol}^{(18)}$. Weighed portions of lung tissue were extracted in chloroform-methanol $(2: 1, \mathrm{v}: \mathrm{v})$ overnight and then processed by the washing procedure of Folch et $a l .{ }^{(27)}$. A portion of each lipid extract was subjected to saponification, after which a known amount of trimethylmethoxyphenyl-retinol was added to each sample as an internal standard. Following reverse-phase HPLC separation with UV detection, the areas of the peaks were quantified by Millenium-32 (Waters) software. 


\section{Gene mRNA level determination}

Total RNA from the lung tissue of individual pups was extracted using a guanidine extraction method and reverse transcribed into its complementary DNA. The diluted reaction product was used for quantitative real-time PCR analysis. Primers designed to detect mRNA for rat LRAT (NM_022280.2), rat CYP26B1 (NM_181087) and rat STRA6 (NM_0010029924.1) were as described previously ${ }^{(16)}$. For IL-6 (NM_012589.1), the primers were: 5'-TGT GCA ATG GCA ATT CTG AT-3' (forward) and 5'-TGG TCT TGG TCC TTA GCC AC-3' (reverse); and for rat chemokine (C-C motif) ligand 2 (CCL2) (NM_031530.1), the primers were 5'-AGG TGT CCC AAA GAA GCT GT-3' (forward) and 5'-TGC TTG AGG TGG TTG TGG AA-3' (reverse). The mRNA expression level for each sample was corrected by calculating the mRNA-to-ribosomal 18S RNA ratio. Data were normalised to the average value for the control group, set at 1.00 prior to statistical analysis.

\section{Statistical analysis}

Data are presented as group means with their standard errors. Differences were tested by one-factor ANOVA followed by Fisher's protected least significant difference test using GraphPad Prism software (GraphPad Software, Inc.). For comparisons, we normalised the mean mRNA value of the control group to 1.00, and the mean values of the other groups were converted accordingly. When variance terms were unequal, values were $\log _{10}$-transformed prior to statistical analysis. Differences with $P<0.05$ were considered significant.

\section{Results}

\section{Markers of inflammation indicate induction of} inflammation

To confirm that inflammation was induced in our neonatal rats, we determined the expression of certain inflammation markers in the lung by real-time PCR and the level of CRP in the serum by ELISA. The IL- 6 and CCL2 are inflammatory mediators in the early inflammatory response and in the evolution of inflammatory events. In the neonatal lung, the expression of these two genes was increased by LPS at $6 \mathrm{~h}$ (Fig. 1(A) and (B)). However, $18 \mathrm{~h}$ after administration of LPS, the levels had returned to the control level (Fig. 1(C) and (D)). On the other hand, plasma CRP, an acute-phase protein produced mainly by the liver, was not increased at $6 \mathrm{~h}$, but was significantly increased at 18h (Fig. 1(E) and (F)). These results demonstrated that neonatal rats that received LPS were experiencing a state of inflammation by $6 \mathrm{~h}$ after LPS treatment, manifested by increased cytokine and chemokine gene expression in the lungs, and a systemic response that developed between 6 and $18 \mathrm{~h}$ and was manifested as an elevation in plasma acute-phase protein.

\section{Lipopolysaccharide-induced inflammation only slightly} reduced the VARA-mediated increase in lung total retinol

In Expt 1, LPS and VARA were administered concurrently to 7to 8-d-old neonatal rats, while in Expt 2, LPS was administered
$12 \mathrm{~h}$ prior to VARA treatment to establish inflammation before treatment with VARA. In both experiments, VARA significantly increased lung RE formation $6 \mathrm{~h}$ after its administration (Fig. 2(A) and (B)). Treatment with LPS alone did not significantly alter the basal level of lung RE. In the $6 \mathrm{~h}$ study, LPS attenuated the increase in RE by VARA by approximately $38 \%$ (Fig. 2(A)). In the $18 \mathrm{~h}$ study, LPS also slightly, but nonsignificantly, reduced the increase in lung RE due to VARA (Fig. 2(B)). In Expt 2, we also conducted a metabolic study by adding a tracer of $\left[{ }^{3} \mathrm{H}\right]$ retinol to the VARA or placebo dose to investigate the uptake of newly absorbed retinol into lung tissue. The percentage of newly absorbed ${ }^{3} \mathrm{H}$ in the lungs of VARA-treated neonatal rats did not differ between the control group and those with inflammation (data not shown). These results suggest that an acute inflammation induced by LPS does not prevent the increase in lung RE formation that is promoted by treatment with VARA.

\section{Lipopolysaccharide-induced inflammation did not} interrupt the induction of stimulated by retinoic acid 6, lecithin:retinol acyltransferase and cytochrome P45026B1 by VARA supplementation

STRA6 and LRAT are likely to function in concert ${ }^{(28)}$ to regulate the uptake and esterification of retinol. RA was shown previously to up-regulate the expression of these genes and to enhance retinol uptake and RE storage in the neonatal lung ${ }^{(16)}$. In the present studies, LPS alone has no effect on the level of STRA6 mRNA and VARA was effective in increasing STRA6 mRNA regardless of treatment with LPS and the time of LPS administration prior to VARA supplementation (Fig. 3(A) and (B)). Similarly, VARA significantly induced LRAT mRNA in both the 6 and $18 \mathrm{~h}$ studies (Fig. 3(C) and (D)). Only in the $6 \mathrm{~h}$ study, LPS slightly reduced the induction of LRAT by VARA, which corresponds with the slight reduction of RE formation observed in the LPS/VARA-treated group.

The expression of CYP26B1, the principal retinoidmetabolising CYP26 form in the lung, which was shown previously to be increased by RA and to remain elevated longer than STRA6 or LRAT after RA or VARA treatment ${ }^{(16)}$, was also examined in LPS-treated neonates. The CYP26B1 mRNA levels were not reduced significantly after treatment with LPS (Fig. 4(A) and (B)). Thus, in both experiments, the expression of these three principal retinoid homeostatic genes was significantly and rapidly increased above the control level $6 \mathrm{~h}$ after VARA supplementation. These results suggested that LPS-initiated inflammation does not prevent the normal response to VARA, either regarding retinol uptake and esterification (Fig. 3) or retinoid oxidation (Fig. 4).

\section{Discussion}

The lung is a major extrahepatic organ that requires VA activity for normal development and function, and has the potential to store VA after VA administration ${ }^{(29,30)}$. We have shown previously that when RA is supplemented simultaneously with VA as VARA, the combination produces a significant synergy, increasing lung RE to a greater extent than an equal amount 
(A)

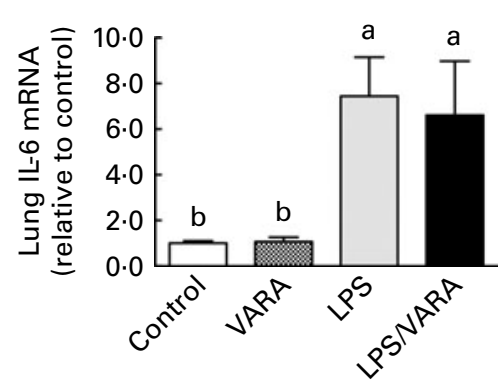

(C)

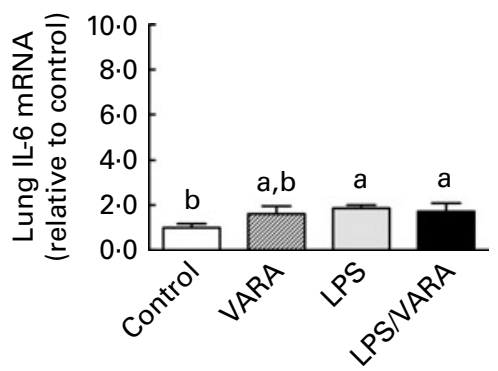

(E)

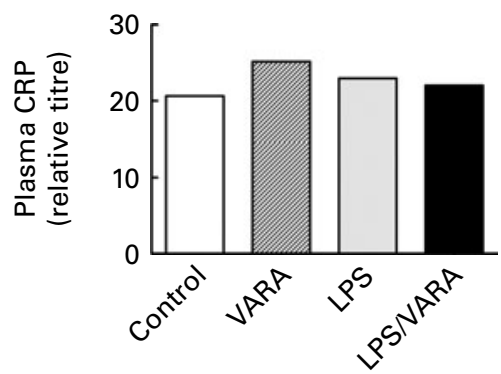

(B)

Expt 2,18h

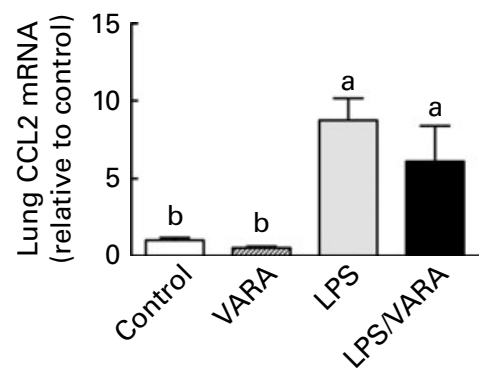

(D)

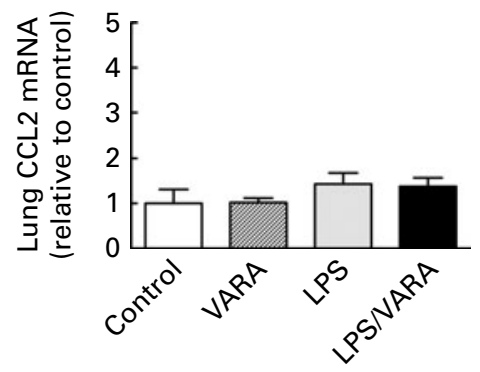

(F)

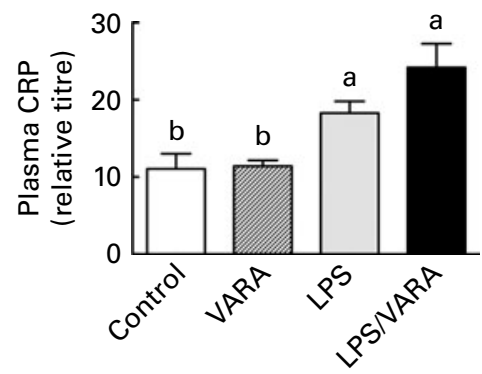

Fig. 1. Expression of lung ( $A, C) I L-6,(B, D)$ chemokine ( $-C$ motif) ligand $2(C C L 2)$ and $(E, F)$ plasma $C$-reactive protein (CRP) determined 6 and $18 \mathrm{~h}$ after administration of lipopolysaccharide (LPS) in VARA-supplemented neonatal rats. Lung tissues were collected $6 \mathrm{~h}$ after VARA treatment and processed for total RNA isolation and subjected to quantitative PCR analysis. In Expt 1, LPS and VARA were administered simultaneously, while in Expt 2, LPS was administered $12 \mathrm{~h}$ before VARA supplementation. Data for IL-6 and CCL2 mRNA were normalised to $18 \mathrm{~S}$ ribosomal RNA and the average value for the control group was set to 1.0 for each experiment. Data for CRP were $\log _{10}$-transformed prior to ANOVA. Values are means, with their standard errors represented by vertical bars except for $(E)$, which represents a single pool for each treatment. ${ }^{a, b}$ Mean values with unlike letters were significantly different $(P<0.05)$.

of VA alone. Moreover, this increase is tissue selective because the synergistic response is not observed in the liver, in which VARA and the same amount of VA alone increased RE content to the same extent ${ }^{(17,18)}$. Therefore, these results have shown that VA uptake and RE storage can be elevated in a tissuespecific manner. However, little is known about retinoid homeostasis in the lung under conditions of inflammation.

It is well known that the condition of hyperoxia usually induces reactive oxygen species, which in turn damage lipids, proteins and nucleic acids in the lung tissue. It has been reported that inflammatory cells in the lungs and depletion of antioxidants, such as acsorbate, occurs time dependently during exposure to hyperoxia ${ }^{(31)}$. Although the roles of VA as antioxidant and anti-inflammatory factors have been explored, it is still controversial as to whether, or under what conditions, VA exerts pro- or anti-inflammatory effects. Pasquali et $a l .{ }^{(32)}$ have reported that, when VA supplementation was introduced to pregnant rats, even in a safe dosage, the lungs of the offspring of these rats contained increased levels of lipo- and protein oxidation products and exhibited induction of antioxidant-defensive enzymes. These changes in the lung tissue revealed a potential for harmful effects of VA supplementation in neonates. However, James et al. ${ }^{(33)}$ recently showed that treatment with VARA of neonatal mice reared by their dams under hyperoxic conditions resulted in a reduction in lung injury due to hyperoxia and attenuated the hyperoxia-induced increase in macrophage inflammatory protein- 2 mRNA and protein in the lungs. Additionally, VARA prevented the hyperoxia-induced increases in gene expression of several pro-inflammatory cytokines (IL-1 $\beta$, IL- 6 and TNF- $\alpha$ ) and hyperoxia-induced reduction of IL-10. Under hyperoxic conditions, VARA promoted a $>5$-fold increase in lung RE concentration compared to control neonatal mice, although the increase was not greater than that by VA alone under hyperoxic conditions. These studies highlight that additional research is needed 
Expt 1,6h

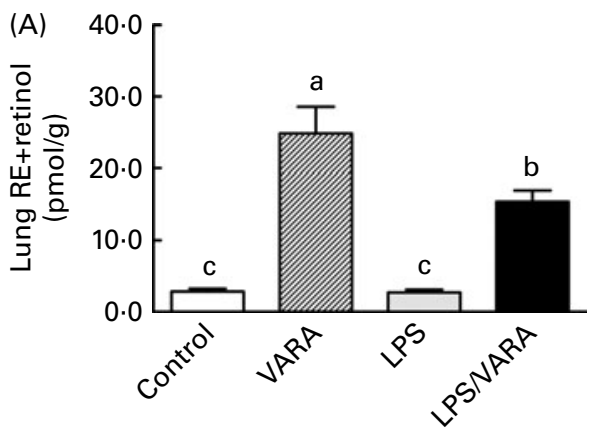

Expt 2,18h

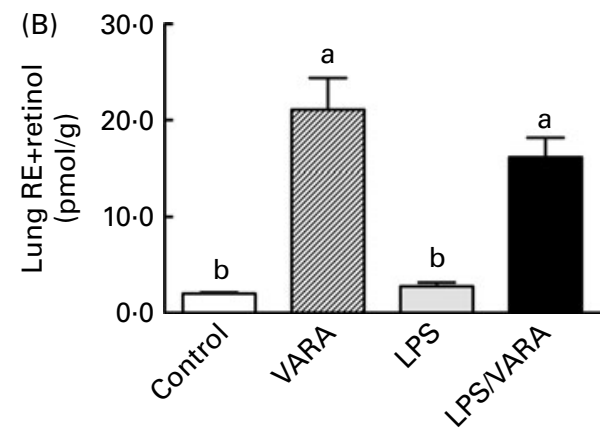

Fig. 2. Lung total retinyl ester (RE) plus retinol concentration (A) $6 \mathrm{~h}$ and (B) $18 \mathrm{~h}$ after administration of lipopolysaccharide (LPS) in VARA-supplemented neonatal rats. Experimental conditions were as described in the legend to Fig. 1. Lung total retinol contents (>90\% RE) were determined by HPLC. Values are means, with their standard errors represented by vertical bars. Data were $\log _{10}$-transformed prior to ANOVA. ${ }^{a, b, c}$ Mean values with unlike letters were significantly different $(P<0 \cdot 05)$.

under conditions relevant to neonatal lung health, such as oxygen therapy and direct VA supplementation, to fully understand the interactions of VA, its metabolite RA and reactive oxygen species and other indicators of oxidative metabolism in the lungs.

In the present study, we initially hypothesised that LPS treatment would interfere with retinoid homeostasis in the lungs, as suggested by previous studies in which LPS-induced inflammation caused a strong attenuation of the RA-induced increase in CYP26A1 and CYP26B1 gene expression in adult rat liver ${ }^{(26)}$. In the present studies in neonatal rats, the increase of the expression of IL- 6 and CCL2 in the lung (indicators of early inflammatory responses) and the increase of CRP protein in plasma (marker of acute inflammation) confirmed that a state of inflammation existed in the neonates. However, the influence of LPS-induced inflammation on VA homeostasis was very mild. The LPS-induced inflammation reduced the increase in RE by approximately 38\% when LPS and VARA were administered concomitantly, and only by approximately $24 \%$, a non-statistically significant difference, when LPS was administered $12 \mathrm{~h}$ before VARA supplementation. The dose of LPS that we used, $200 \mu \mathrm{g} / \mathrm{kg}$ of body weight, was lower compared to the dose of $500 \mu \mathrm{g} / \mathrm{kg}$ used previously in adult rats $^{(34,35)}$, because we found that neonates did not survive treatment with the adult dose. Overall, we believe that the conditions in the present study were representative of LPS-induced inflammation in this age group. The present quantitative PCR data for STRA6, LRAT and CYP26B1 also

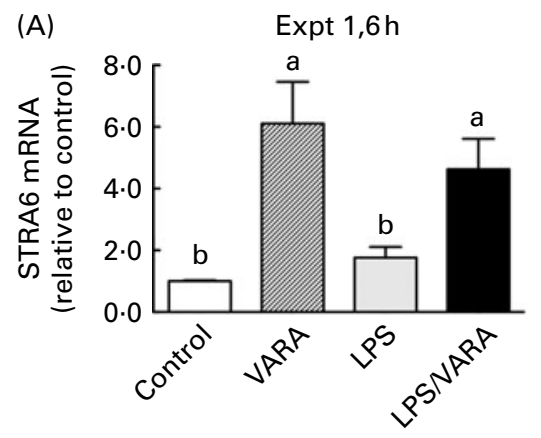

(B)

Expt 2,18h

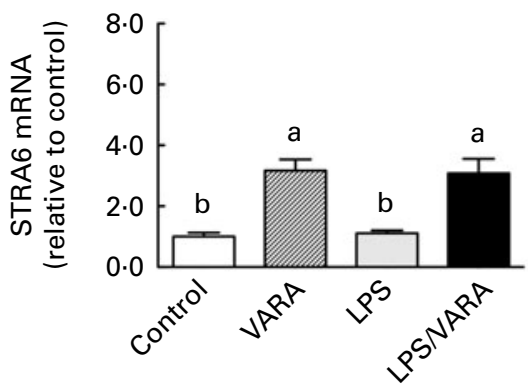

(C)

(D)
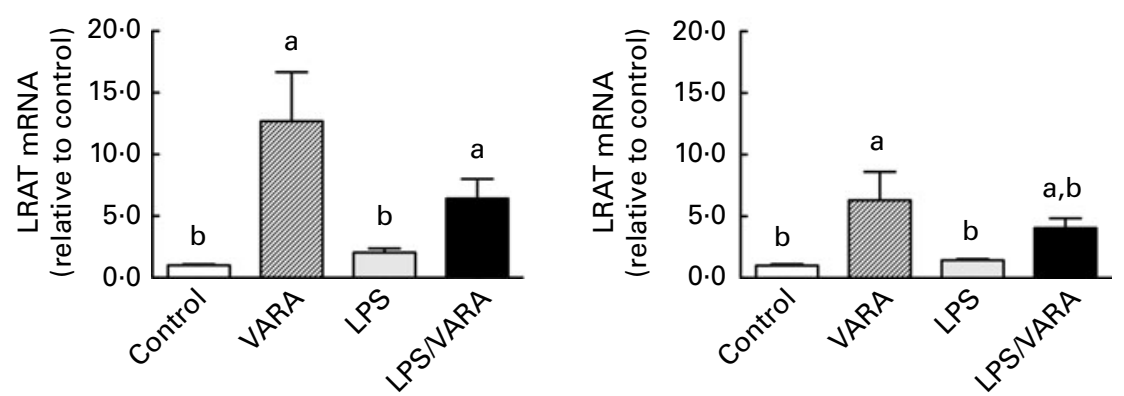

Fig. 3. (A, B) Stimulated by retinoic acid 6 (STRA6) and (C, D) lecithin:retinol acyltransferase (LRAT) mRNA expression 6 and $18 \mathrm{~h}$ after administration of lipopolysaccharide (LPS) in VARA-supplemented neonatal rats. Experimental conditions were as described in the legend to Fig. 1. Data were normalised to 18S ribosomal RNA and the average value for the control group was set at 1.0 for each experiment. Values are means, with their standard errors represented by vertical bars. Data were $\log _{10}$-transformed prior to ANOVA. ${ }^{a, b}$ Mean values with unlike letters were significantly different $(P<0.05)$. 

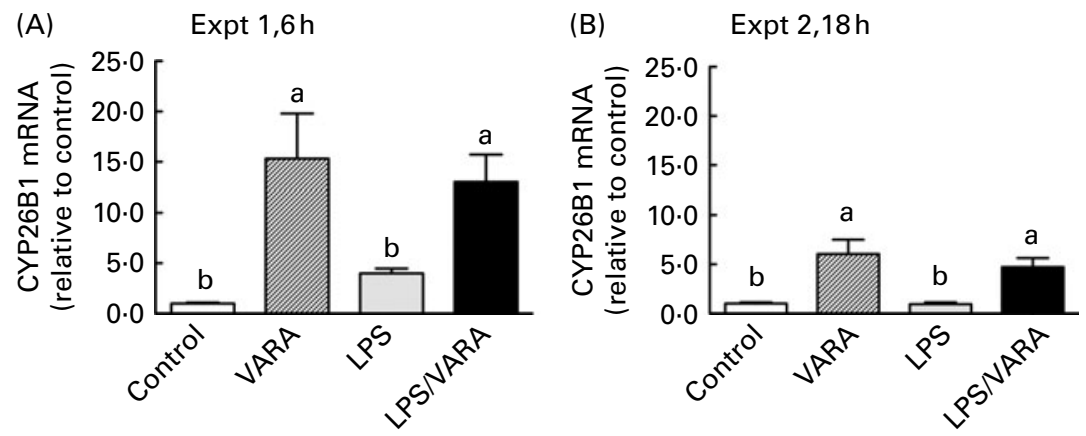

Fig. 4. Cytochrome P450 26B1 (CYP26B1) mRNA expression (A) $6 \mathrm{~h}$ and (B) $18 \mathrm{~h}$ after administration of lipopolysaccharide (LPS) in VARA-supplemented neonatal rats. Experimental conditions were as described in Fig. 1. Data were normalised to $18 \mathrm{~S}$ ribosomal RNA and the average value for the control group was

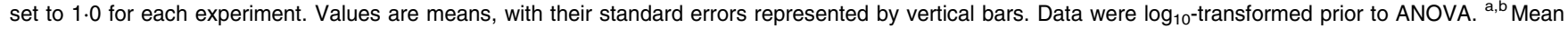
values with unlike letters were significantly different $(P<0.05)$.

indicated that the inflammation state had little influence on retinoid homeostasis, either with or without VARA supplementation. In clinical situations in which exposure to LPS is principally due to infection with Gram-negative bacteria, additional factors related to infection and/or the host response to bacterial infection could modulate retinoid homeostasis in ways not observed in the present study. Additional studies are also needed in other models. However, the present study suggests that the lung's ability to esterify retinol derived from newly absorbed VA and to store the resulting RE may not be compromised during a state of moderate inflammation.

The present data on lung RE content and retinoid homeostatic gene expression for the groups of neonates that were treated with LPS only are also of interest. These results suggest that the concentration of endogenous VA, derived by transfer from the mother, and levels of expression of retinoid homeostatic genes, in the lungs in the absence of VARA supplementation, are not greatly altered by acute lung inflammation. Overall, the results of the present study suggest that, even in a state of moderate inflammation, VARA could still be an effective therapeutic strategy for improving VA status in the neonatal lung.

Although VA and RA were admixed in the VARA preparation, there is reasonable evidence that they are absorbed independently, with the VA component being absorbed as $\mathrm{RE}$ in chylomicrons and the RA component (and any RA produced from the newly absorbed VA in the intestine) being absorbed into the portal vein ${ }^{(36)}$. Chylomicron $\mathrm{RE}$ are rapidly removed, mostly into liver, but with some uptake by extrahepatic tissues, including the lungs, as shown in $\left[{ }^{3} \mathrm{H}\right]$ retinol tracer studies ${ }^{(18)}$. The RA in plasma is rapidly cleared, with a half-life of a few minutes ${ }^{(37,38)}$. It therefore appears that the greatest effect of VARA occurs in the immediate absorptive period after dosing. This is further supported by a maximal increase in lung RE within approximately $6 \mathrm{~h}$ after oral administration of VARA. Our previous studies suggest that the regulation of retinoid homeostatic genes is attributable to the RA component of VARA or surrogate acidic retinoids with RA-like activity ${ }^{(16)}$, but the strong accumulation of RE in the neonatal lungs necessarily requires administration of retinol, delivered as the VA component of the VARA dose ${ }^{(16,18)}$. Thus, both components of the VARA dose are effective together, through their different mechanisms, even in a state of moderate inflammation. In terms of their relative turnover rates, RA is rapidly catabolised, while retinol has an intermediate turnover rate and RE is a very stable form of VA that can be stored in tissues for long periods as well as mobilised to form retinol again. Treatment with VARA results in the lung 'seeing' a short-term pulse of RA, resulting in changes in gene expression, as well as a more persistent uptake of retinol from holo-retinol-binding protein or possibly RE from chylomicrons, which can be stored in the tissues as RE. The RE stored in the tissue can be hydrolysed to provide substrate for the production of RA, and, hence, maintenance of steady-state levels of retinoids over time. Given the promising results noted earlier, for RA therapy in promotion of alveolarisation and tissue repair in neonatal and adult models of lung disease $^{(7-10)}$, VARA supplementation could potentially facilitate similar effects through its rapid provision of RA and longer-term provision of retinol for esterification and storage. However, not all studies using RA have been effective and new strategies are needed. Because RA cannot be reduced in vivo to generate retinol or its esters, the VARA combination, which provides both RA and retinol, could be advantageous as a more stable and longer-acting treatment for inducing lung differentiation and promoting the repair of damaged tissue.

\section{Acknowledgements}

We thank the members of our laboratory for assistance with animal experiments. This work was supported by the National Institutes of Health grants CA-090214 and HD-066982 (to A. C. R.). The authors have no disclosures. Both authors have read and approved the final version. L. W. designed and conducted the research and prepared the draft manuscript; A. C. R. planned and designed the research and prepared the final manuscript. The authors have no potential financial conflict of interest.

\section{References}

1. Zachman RD \& Grummer MA (2000) Retinoids and lung development. In Contemporary Endocrinology: Endocrinology of the Lung: Development and Surfactant Synthesis, 
pp. 161-179 [RD Zachman and MA Grummer, editors]. Totowa, NJ: Humana Press, Inc.

2. Mactier H \& Weaver LT (2005) Vitamin A and preterm infants: what we know, what we don't know, and what we need to know. Arch Dis Child Fetal Neonatal Ed 90, F103-F108.

3. Guimarães H, Guedes MB, Rocha G, et al. (2012) Vitamin A in prevention of bronchopulmonary dysplasia. Curr Pharm Des 18, 3101-3113.

4. Shenai JP, Kennedy KA, Chytil F, et al. (1987) Clinical trial of vitamin A supplementation in infants susceptible to bronchopulmonary dysplasia. J Pediatr 111, 269-277.

5. Tyson JE, Wright LL, Oh W, et al. (1999) Vitamin A supplementation for extremely-low-birth-weight infants. National Institute of Child Health and Human Development Neonatal Research Network. N Engl J Med 340, 1962-1968.

6. Ambalavanan N, Tyson JE, Kennedy KA, et al. (2005) Vitamin A supplementation for extremely low birth weight infants: outcome at 18 to 22 months. Pediatrics 115, e249-e254.

7. Fraslon C \& Bourbon JR (1994) Retinoids control surfactant phospholipid biosynthesis in fetal rat lung. Am J Physiol Lung Cell Mol Physiol 266, L705-L712.

8. Maden M \& Hind M (2004) Retinoic acid in alveolar development, maintenance and regeneration. Philos Trans $R$ Soc Lond B Biol Sci 359, 799-808.

9. Belloni PN, Garvin L, Mao CP, et al. (2000) Effects of alltrans-retinoic acid in promoting alveolar repair. Chest 117, Suppl. 1, 235S-241S.

10. McGowan SE (2002) Contributions of retinoids to the generation and repair of the pulmonary alveolus. Chest 121, 5 Suppl., 206S-208S.

11. Tang XH \& Gudas LJ (2011) Retinoids, retinoic acid receptors, and cancer. Annu Rev Pathol 6, 345-364.

12. Duong V \& Rochette-Egly C (2011) The molecular physiology of nuclear retinoic acid receptors. From health to disease. Biochim Biophys Acta 1812, 1023-1031.

13. Fields AL, Soprano DR \& Soprano KJ (2007) Retinoids in biological control and cancer. J Cell Biochem 102, 886-898.

14. Kawaguchi R, Yu J, Honda J, et al. (2007) A membrane receptor for retinol binding protein mediates cellular uptake of vitamin A. Science 315, 820-825.

15. Ross AC \& Zolfaghari R (2011) Cytochrome P450s in the regulation of cellular retinoic acid metabolism. Annu Rev Nutr 31, 65-87.

16. Wu L \& Ross AC (2010) Acidic retinoids synergize with vitamin A to enhance retinol uptake and STRA6, LRAT, and CYP26B1 expression in neonatal lung. J Lipid Res $\mathbf{5 1}$, 378-387.

17. Ross AC, Li NQ \& Wu L (2006) The components of VARA, a nutrient-metabolite combination of vitamin A and retinoic acid, act efficiently together and separately to increase retinyl esters in the lungs of neonatal rats. J Nutr 136, 2803-2807.

18. Ross AC, Ambalavanan N, Zolfaghari R, et al. (2006) Vitamin A combined with retinoic acid increases retinol uptake and lung retinyl ester formation in a synergistic manner in neonatal rats. J Lipid Res 47, 1844-1851.

19. Darlow BA \& Graham PJ (2002) Vitamin A supplementation for preventing morbidity and mortality in very low birthweight infants. The Cochrane Database of Systematic Reviews, issue 4 CD000501.

20. Speer CP (2006) Inflammation and bronchopulmonary dysplasia: a continuing story. Semin Fetal Neonatal Med 11, $354-362$.
21. Speer CP (2003) Inflammation and bronchopulmonary dysplasia. Semin Neonatol 8, 29-38.

22. Groneck P, Gotze-Speer B, Oppermann M, et al. (1994) Association of pulmonary inflammation and increased microvascular permeability during the development of bronchopulmonary dysplasia: a sequential analysis of inflammatory mediators in respiratory fluids of high-risk preterm neonates. Pediatrics 93, 712-718.

23. Groneck P, Schmale J, Soditt V, et al. (2001) Bronchoalveolar inflammation following airway infection in preterm infants with chronic lung disease. Pediatr Pulmonol 31, 331-338.

24. Jobe AH \& Ikegami M (1998) Mechanisms initiating lung injury in the preterm. Early Hum Dev 53, 81-94.

25. Morgan ET, Li-Masters T \& Cheng PY (2002) Mechanisms of cytochrome $\mathrm{P} 450$ regulation by inflammatory mediators. Toxicology 181-182, 207-210.

26. Zolfaghari R, Cifelli CJ, Lieu SO, et al. (2007) Lipopolysaccharide opposes the induction of CYP26A1 and CYP26B1 gene expression by retinoic acid in the rat liver in vivo. Am J Physiol Gastrointest Liver Physiol 292, G1029-G1036.

27. Folch J, Lees M \& Sloane Stanley GH (1957) A simple method for the isolation and purification of total lipides from animal tissues. J Biol Chem 226, 497-509.

28. Kawaguchi R, Yu J, Ter-Stepanian M, et al. (2011) Receptormediated cellular uptake mechanism that couples to intracellular storage. ACS Chem Biol 6, 1041-1051.

29. Nagy NE, Holven KB, Roos N, et al. (1997) Storage of vitamin A in extrahepatic stellate cells in normal rats. J Lipid Res $\mathbf{3 8}$, 645-658

30. Shenai JP \& Chytil F (1990) Vitamin A storage in lungs during perinatal development in the rat. Biol Neonate 57, 126-132.

31. Pace PW, Yao LJ, Wilson JX, et al. (2009) The effects of hyperoxia exposure on lung function and pulmonary surfactant in a rat model of acute lung injury. Exp Lung Res 35 380-398.

32. Pasquali MA, Schnorr CE, Feistauer LB, et al. (2010) Vitamin A supplementation to pregnant and breastfeeding female rats induces oxidative stress in the neonatal lung. Reprod Toxicol 30, 452-456.

33. James ML, Ross AC, Bulger A, et al. (2010) Vitamin A and retinoic acid act synergistically to increase lung retinyl esters during normoxia and reduce hyperoxic lung injury in newborn mice. Pediatr Res 67, 591-597.

34. Rosales FJ, Ritter SJ, Zolfaghari R, et al. (1996) Effects of acute inflammation on plasma retinol, retinol-binding protein, and its mRNA in the liver and kidneys of vitamin A-sufficient rats. J Lipid Res 37, 962-971.

35. Rosales FJ \& Ross AC (1998) Acute inflammation induces hyporetinemia and modifies the plasma and tissue response to vitamin A supplementation in marginally vitamin Adeficient rats. J Nutr 128, 960-966.

36. Ross AC \& Harrison EH (2007) Vitamin A: nutritional aspects of retinoids and carotenoids. In Handbook of Vitamins, pp. 1-40 [J Zempleni, RB Rucker and DB McCormick, et al., editors]. Boca Raton, FL: Taylor, Francis Group.

37. Kurlandsky SB, Gamble MV, Ramakrishnan R, et al. (1995) Plasma delivery of retinoic acid to tissues in the rat. $J$ Biol Chem 270, 17850-17857.

38. Cifelli CJ \& Ross AC (2006) All-trans-retinoic acid distribution and metabolism in vitamin A-marginal rats. Am J Physiol Gastrointest Liver Physiol 291, G195-G202. 